\title{
Facing the future: Scanning, synthesizing and sense-making in horizon scanning
}

\author{
Totti Könnölä ${ }^{1, *}$, Ahti Salo ${ }^{2}$, Cristiano Cagnin ${ }^{3}$, Vicente Carabias $^{4}$ and \\ Eeva Vilkkumaa ${ }^{2}$ \\ ${ }^{1}$ Impetu Solutions, Victor Andrés Belaunde, 36-4C, 28016 Madrid, Spain \\ ${ }^{2}$ Aalto University School of Science, Department of Mathematics and Systems Analysis, \\ PO Box 11100, 00076 Aalto, Finland \\ ${ }^{3} E U$ DG JRC-IPTS, Seville, Spain; and Center for Strategic Studies and Management (CGEE), \\ SCN Qd 2, Bl. A, Ed. Corporate Financial Center, Sl. 1112, 70712-900, Brasília-DF, Brasil \\ ${ }^{4} E U$ DG JRC-IPTS, Seville, Spain; and ZHAW Zurich University of Applied Sciences, Institute of \\ Sustainable Development, Postfach 805, CH-8401 Winterthur, Switzerland \\ *Corresponding author. Email: totti.konnola@impetusolutions.com.
}

\begin{abstract}
In this paper, we discuss key issues in harnessing horizon scanning to shape systemic policies, particularly in the light of the foresight exercise 'Facing the future: Time for the EU to meet global challenges' which was carried out for the Bureau of European Policy Advisors. This exercise illustrates how horizon scanning can enable collective sense-making processes which assist in the identification of emerging signals and policy issues; the synthesis of such issues into encompassing clusters; and the interpretation of resulting clusters as an important step towards the coordinated development of joint policy measures. In order to achieve such objectives, horizon scanning can benefit from methods of multi-criteria decision-making and network analysis for prioritizing, clustering and combining issues. Furthermore, these methods provide support for traceability, which in turn contributes to the enhanced transparency and legitimacy of foresight.
\end{abstract}

Keywords: horizon scanning; foresight; grand challenges; policy coordination; futures.

\section{Introduction}

In future-oriented technology analysis (FTA), the systematic exploration of divergent views on future developments has tended to receive less attention than approaches that foster consensus seeking (Könnölä et al. 2011; Martin and Johnston 1999; Georghiou and Cassingena Harper 2011). At present, however, various forms of horizon scanning are gaining in popularity, as evidenced by the considerable interest that practitioners and policy-makers have expressed in exploring alternative and even conflicting interpretations of the future (Kuosa 2010; Rossel 2011; Saritas and Smith 2011).

While the intellectual origins of 'horizon scanning' can be traced to the celebrated work by Ansoff (1975) on the recognition of weak signals, the term was popularized and institutionalized in the UK after the millennium (Schultz 2006). For example, the Department for Environment,
Food and Rural Affairs (DEFRA) defined horizon scanning in 2002 as:

...the systematic examination of potential threats, opportunities and likely future developments which are at the margins of current thinking and planning' and, continuing, horizon scanning 'may explore novel and unexpected issues, as well as persistent problems or trends. ${ }^{1}$

At present, various forms of horizon scanning are quite widespread (Amanatidou et al. 2012), even to the point where it is not easy to take stock of those activities that do not readily fit under any single label. Despite this variability, horizon scanning offers tested approaches for collecting signals which:

- Articulate credible observations about current or imminent changes (either sudden, gradual, or between these poles). 
- Are felt to be potential indications of new emerging issues that may have received insufficient attention.

- Can be meaningfully shared, elaborated and assessed by the participants.

Arguably, the growing interest in horizon scanning and further on the apparently greater empirical reliance of horizon scanning over scenario planning reflect the increasing complexity of modern societies which are continually shaped by so many uncertainties especially in the social and political spheres. This indicates that FTA approaches based on linear extrapolation or causal modelling do not suffice (Linstone 1999).

In this setting, where policy-makers are almost bound to be taken by surprise, horizon scanning can serve as a systematic approach to support the early identification and collective exploration of emerging issues. This can be seen as a step towards the timely implementation of appropriate policy actions. Here, the need for horizon scanning is effectively intensified by the long lead times for bringing about desired policy impacts (cf. climate change mitigation). Taking this remark further, horizon scanning may offer major benefits especially when there are long delays in policy implementation and when the issues evolve through an incipient phase that is initially only observed by some individuals. While individual sense-making has been aptly recognized as a key determinant of what signals are 'relevant', the collective sense-making processes coupled with the interpretation of signals have received less attention, particularly with regard to the recognition of interconnections among the signals or the derivation of their policy implications (Dervin 1998). These collective processes are also important because they underlie key scoping decisions and thus shape both implicit and explicit expectations that influence scanners and their behaviour. In this paper, we elucidate these processes in the light of the horizon scanning exercise 'Facing the future: Time for the EU to meet global challenges', which was carried out in 2009 by the Joint Research Centre - Institute for Prospective Technological Studies (JRC-IPTS) for the Bureau of European Policy Advisors (BEPA) of the European Commission (EC). It should be noted that this exercise was not limited to the scanning of signals: rather, it sought to achieve greater visibility and coherence by synthesizing signals into cross-cutting challenges whose policy implications were then explored in a workshop. By building on the encouraging experiences of this exercise, we outline methodological steps in support of comparable scanning processes which facilitate the incremental development of cross-cutting challenges so that traceable links between these challenges and their underlying signals and sources are established. Finally, we argue that these types of scanning processes can be viewed as an instrument that prepares ground for cross-cutting policy coordination and the attainment of systemic policy objectives.

\section{Sense-making in horizon scanning}

Because the objective of horizon scanning is to create knowledge on the emergence of issues that, by definition, lie beyond current horizons, there is often only scarce and scattered evidence to support the collection of signals and the assessment of their significance. It therefore follows that scanners need to leverage tacit knowledge (Nonaka 1994) which reflects their experiences and interpretations of perceived reality (Scharmer 2000). On this point, Weick (1995) argues that sense-making is not mere interpretation: in fact, it is less about discovery and more about invention. In a similar tone, Möller (2010) states that:

... before something, an idea or object, can be sensed, it has to be constructed.

This construction is essentially a collective activity of knowledge creation. Against this backdrop, we regard horizon scanning as: a creative process of collective sense-making by way of collecting and synthesizing observations that hold potential for the elaboration of pertinent future developments and the derivation of actionable implications for decision-making.

At the individual level, sense-making builds on the actor's ability to perceive, interpret and construct the meaning of the emerging landscape (du Toit 2003; Nelson 2010; Weick 1995). Yet the broader significance of this individual sense-making is built collectively, for instance when observations are evaluated or aggregated into more encompassing clusters or when their interrelationships with other notions, such as trends, are explored.

\subsection{Scoping the scanning exercise}

Early on, the scoping of a scanning exercise necessitates fundamental methodological decisions that partly demarcate which signals are likely to appear relevant. Some exercises have sought to scan across a truly comprehensive spectrum (Glenn et al. 2010; Saritas and Smith 2011), while others have focused on specific fields such as telemedicine (Blackburn et al. 2010), security (Botterhuis et al. 2010), environmental conservation (Sutherland et al. 2011), or energy, health and cognitive enhancement (Amanatidou et al. 2012). Dedicated centres have been established to provide horizontal support for government departments (e.g. Horizon Scanning Centres in the UK and Singapore; the National Intelligence Council in the USA; and the OECD Futures Programme). Methodological advances have been pursued, for instance, in the Framework Programme 7 Blue Sky Foresight projects on emerging issues that shape European science and technology (Amanatidou et al. 2012).

In effect, scoping involves more or less conscious sense-making processes of which future developments are 
potentially significant and thus worth scanning. Here, there may be bias to align scanning exercises along well-established fields or to follow path-dependent institutional structures (Könnölä and Unruh 2007) that reflect, for instance, the mandate of the client or sponsor, or the expected uses of results. But even if the scope of scanning is left rather open, other design issues, such as available resources or the duration of the exercise, may impose comparable bounds.

\subsection{Sense-making: Inseparable from scanning}

Defining 'what' specifically is to be scanned is just as important as demarcating the scope of the scanning activity. Saritas and Smith (2011), for instance, consider trends, drivers of change, wild cards/shocks, discontinuities, and weak signals as meaningful units to be scanned. Kuosa (2010) notes that the widely used, but somewhat imprecise, concept of weak signals 'seems to be everything and anything that is related to substantial potential change' before he elaborates an alternative scanning framework that embodies concepts such as weak signals, drivers and trends. On a somewhat different note, Könnölä et al. (2007) argue that the collection of weak signals tends to produce relatively unstructured pools of signals and propose the use of narrower 'units of analysis' that are more amenable to subsequent analyses. All in all, it is important to realize that decisions about the definition of units do guide what future-relevant observations will be submitted (Hiltunen 2008; Mendonça et al. 2004).

Especially in the case of weak signals and wild cards, sense-making builds on the scanners' creative and heuristic capabilities to detect meaningful observations in the presence of scattered or no historical evidence (Dervin 1998). But even if there is historical evidence to support the seemingly straightforward extrapolation of trends, assessing such trends in relation to individual signals still permits alternative interpretations that can be reached only through sense-making. Moreover, the most interesting emerging issues may be ambiguous, characterized by nebulous cause-and-effect relationships between existing and emergent knowledge. Seen from this perspective, sense-making can be partly supported by defining units of analysis that facilitate the collection of individual observations and, moreover, the creative combination thereof to permit the creation of new entities and meanings (Nonaka 1994).

Scanning systems may comprise quantitative methods such as bibliometrics, cybermetrics and patent analysis, which may also convey patterns of emerging issues. The deployment of these methods and the interpretation of their results in terms of requisite actions builds on individual and collective sense-making activities. Thus, it appears that whatever the methodological basis of scanning is, sense-making lies at the heart of providing well-founded support for policy-making.

\subsection{Stakeholders: Crucial for scanning and synthesizing}

The strong reliance on scanners in soliciting signals raises questions about who are legitimate 'scanners' and how the different and even contradictory submissions of these scanners can be synthesized? The consultation of recognized experts in scanning may lend credibility to the exercise and its results. But one can also argue that the very remit of horizon scanning is to challenge the mindsets of esteemed incumbents whose perceptions may reflect well-established evidence rather than surprising interpretations of incipient developments (Taleb 2007).

Here, we argue that horizon scanning should seek to engage diverse stakeholders (Könnölä et al. 2007). Such diversity can be operationalized by formulating explicit criteria such as: the coverage of different fields of expertise, types of affiliations, cultural backgrounds, organizational functions or personal values. Furthermore, engaging diverse stakeholders may result in a richer set of initial observations, after which the stakeholders can be engaged further by assessing the significance of these observations in view of interdependencies which, for instance may allow new meanings (Nonaka 1994) to be synthesized through the shared development of cross-cutting challenges. From a methodological perspective, internet-based tools for continuous idea generation (Graefe et al. 2010), idea management and surveys (Haegeman et al. 2011; McKinsey \& Company 2009; Saritas and Smith 2011), for instance, can be effective in collecting and assessing observations as well as in synthesizing these inputs (Könnölä et al. 2007; Salo et al. 2009) in preparation for subsequent face-to-face stakeholder workshops.

\subsection{Building ground for cross-cutting policy coordination}

At best, participatory workshop activities offer policymakers an inspiring environment where they can openly discuss the implications of alternative future developments for policy-making in general as well as for their own responsibilities in particular. Such workshops may also aspire to support vision-building and priority-setting and engage policy-makers and other stakeholders in creative networking that facilitates the implementation of later action plans (Brummer et al. 2008; Fuerth 2009).

From the process perspective, this type of direct engagement in workshops helps expose policy-makers to the diversity of issues at stake. However, when attempting to take issues forward in policy formulation, it is often necessary to synthesize them into meaningful clusters that exhibit a logical structure and are linked to existing decision-making structures (Georghiou and Csaaingena Harper 2011). This is because the mere listing of issues appears so fragmented that it does not lead to the development of overarching policy agendas, expressed as coherent and cross-cutting challenges that can be 


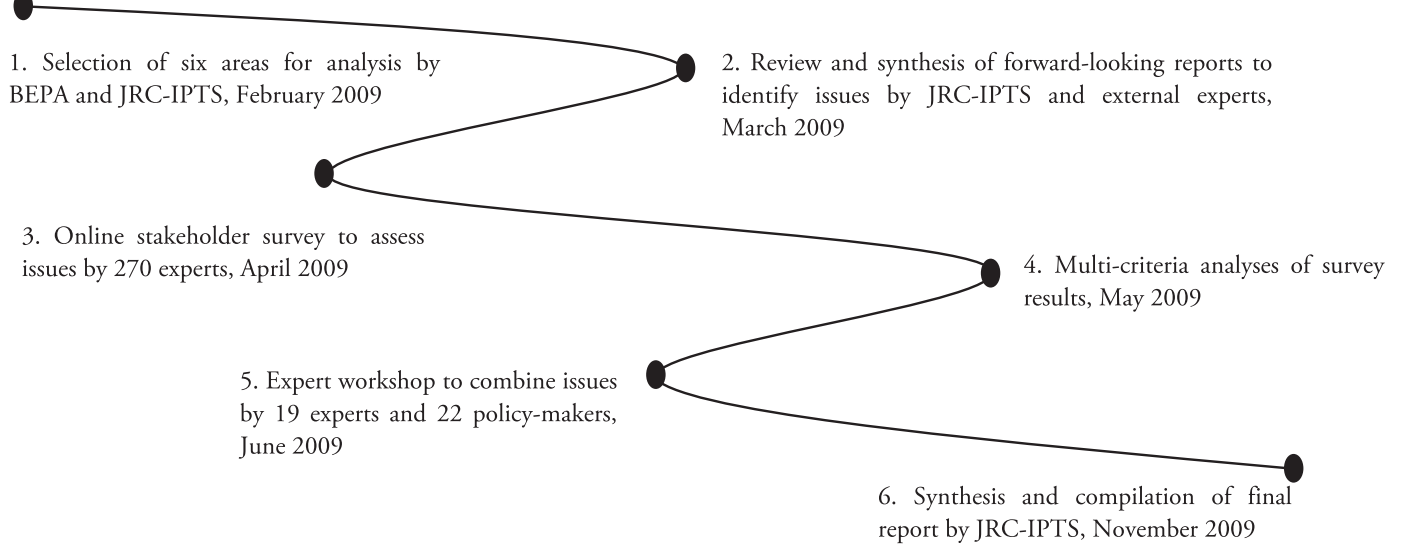

Figure 1. Timeline and phases of foresight exercise 'Facing the future' (Boden et al. 2010).

addressed with systemic policies that span several areas of administrative responsibility. This suggests that horizon scanning can benefit from methods that provide explicit support for the synthesis of relevant combinations (e.g. by using multi-criteria models in the assessment of issues or network models in the analysis of interrelationships), whereby the role of such methods is to foster sense-making (but not to overrule it). Such methods can also support traceability, which contributes to transparency and the legitimacy of the exercise.

Overall, the collaborative development of cross-cutting challenges may help reframe the 'bigger picture' whose exploration paves way for policy coordination and the attainment of systemic policy objectives (Schoen et al. 2011). This is likely to be true especially in policy contexts where the issues are not yet prominent on the agenda and where they evolve interdependently in a problem context where policy actions need to be coordinated and implemented early on to ensure success. There are also opportunities for mutual learning, because different departments and agencies may be faced with shared challenges which can be addressed through responses that exhibit similarities or synergies. Thus, horizon scanning can facilitate cross-cutting coordination and, by doing so, foster the development of joint policy measures without necessitating potentially time-consuming and cumbersame changes in existing organizational structures and practices (Anderson 2005).

\section{Case: Facing the future}

In 2008-9, the BEPA of the EC organized a series of foresight activities (European Communities 2009; Boden et al. 2010) which focused on long-term developments and their policy implications on EU policy-making, as a means of preparing for the development of the Europe 2020 strategy and related policy initiatives such as the EC Communication on the Innovation Union.
In this context, JRC-IPTS and BEPA started collaborative horizon scanning efforts which evolved gradually from initial exchanges of relevant foresight studies to more systematic, comprehensive scanning and detailed analysis of reports, with the aim of identifying future trends and disruptive events that could have major implications on EU policy-making by 2025 (cf. Fig. 1). Furthermore, JRC-IPTS proposed that a robust portfolio modelling (RPM) screening process (Könnölä et al. 2007; Brummer et al. 2008, 2011) would be conducted to engage a wider community of experts in the assessment of key findings from these reports towards the identification of most pertinent issues. Finally, a stakeholder workshop was organized in order to take stock of these issues and, specifically, to make sense of them in terms of cross-cutting challenges and policy implications.

\subsection{Identification of Issues}

BEPA and JRC-IPTS initiated the analysis in six broad areas following the structure of previous work that had been delivered to BEPA by other EC services. JRC-IPTS and BEPA refined these areas through close interaction to accommodate a more comprehensive analysis across all economic sectors and responsibilities of BEPA. The final six areas analysed were:

- demography, migration and health

- economy, trade and financial flows

- environment, energy, climate change and agriculture

- research, innovation and (e)-education

- (e)-governance and (e)-social cohesion

- defence and security

It was then agreed that in each area JRC-IPTS experts would analyse about 20-25 forward-looking reports which had been recently published by international organizations or the business sector; covered more than one of six areas being analysed; exhibited global scope; and had been 
developed using a participatory approach. BEPA emphasized that policy relevance was a crucial criterion in the selection of these reports. Thus, a few policy documents that had been developed on the basis of a participatory approach and subjected to an open consultation were also included.

A total of 129 such reports were reviewed by JRC-IPTS and external experts ${ }^{2}$ following common guidelines concerning the identification and refinement of issues from the reports in two phases:

- Issue recognition by individuals consisted of the identification and codification of specific issues which included both evidence-based and new emerging trends, wild cards and even brief descriptions of anticipated impacts and prospective policy recommendations. Here, the reviewers were requested to rely on their own individual judgement when selecting issues and outlining them for further analysis.

- Bilateral and collective discussions between experts and JRC-IPTS helped to synthesize relevant issues into an interim report. In particular, these creative constructions allowed individual experts to codify their tacit knowledge about possible interlinkages among trends and wild cards as well as related policy recommendations.

These reviews resulted in the jointly authored area descriptions and the identification of 370 codified and traceable issues. These issues were complemented with additional issues from the FTA 2008 conference survey. ${ }^{3}$

\subsection{Assessment of issues}

The formulated issues were assessed in an online survey by some 270 external experts who represented foresight practitioners, EC officials, researchers, non-governmental organizations and business representatives from all the thematic areas that were represented. Specifically, these experts were requested to generate additional issues and to assess all the issues using three criteria:

- relevance to EU policy-making

- novelty in comparison with earlier policy debates

- probability of occurrence by 2025

In total, 381 issues were evaluated on a seven-point Likert-scale which extended from one (issues that are totally lacking in relevance/novelty/probability) to seven (issues that exhibit a very high degree of relevance/ novelty/probability). ${ }^{4}$

\subsection{Analysis of issues}

In order to support the identification of most pertinent issues, the expert assessments were synthesized with the RPM tool (Liesiö et al. 2007; Könnölä et al. 2007).
In the RPM framework, the criterion-specific scores $v_{i}^{j}$ for each issue $j=1, \ldots, m$ are aggregated using the weighted sum:

$$
V^{j}(w)=w_{1} v_{1}^{j}+w_{2} v_{2}^{j}+w_{3} v_{3}^{j}
$$

In contrast to conventional multi-criteria methods, RPM admits incomplete weight information expressed through linear inequalities like $w_{1}>w_{2}>w_{3}$, which, for instance, indicates that the first criterion is the most important, followed by the second and then the third. Specifically, based on a comparative analysis of the overall values $V^{j}(w)$ for different criterion weights, the RPM analysis helps identify

- Core issues which belong to all non-dominated portfolios, defined (in an approximate sense) as those collections of issues for which no other portfolio would yield a higher overall value for all stated weight information.

- Exterior issues that belong to no such portfolios.

- Borderline issues which are in some but not all non-dominated portfolios.

Three different analyses were conducted to highlight different aspects of relevance: mean-oriented analysis, variance-oriented analysis and rare event-oriented analysis. In each analysis, attention was given particularly to the top-10 issues with the highest core index values among all issues in a given area (there were $42-90$ issues in the areas).

3.3.1 Mean-oriented analysis. Mean-oriented analysis helped identify issues that were considered relevant, novel and probable by the majority respondents, whereby the criterion-specific scores $v_{i}^{j}$ were obtained by taking the means of the respondents' assessments. Then, the overall value $V^{j}(w)$ was then computed for each issue such that relevance was seen as the most important criterion, followed by novelty and probability, i.e., $w_{1}>w_{2}>w_{3}$. Because the relevance criterion had the highest weighting, the core issues identified in this analysis seemed to be the most relevant for $\mathrm{EU}$ policy-making.

3.3.2 Variance-oriented analysis. Variance-oriented analysis was conducted in order to recognize issues on which the respondents had different viewpoints. Thus, the scores $v_{i}^{j}$ were defined by the variances of the respondents' criterion-specific assessments. The variance of assessment of novelty was regarded as the most important criterion, followed by variances of relevance and probability, i.e. $w_{1}>w_{2}>w_{3}$. This analysis helped identify issues that the respondents did see similarly, which provided interesting inputs for debate in the final workshop. 
3.3.3 Rare event-oriented analysis. Rare eventoriented analysis was carried out to identify those issues that the respondents considered improbable but still novel and relevant. Here, the scores for relevance and novelty were similar as in the mean-oriented analysis, but $v_{3}^{j}$ was defined such that the issues with the lowest occurrence probabilities received the highest scores, i.e. $v_{3}^{j}=8$, being the average of the probability assessments. Furthermore, this criterion was assigned the highest weight so that $w_{1}>w_{2}>w_{3}$. As a rule, this analysis helped to identify issues which were deemed unlikely but potentially of high significance in terms of their consequences.

All in all, the three complementary RPM analyses helped to highlight issues which were seen to merit attention from different perspectives and thus paved way for the formulation of cross-cutting challenges.

\subsection{Synthesizing issues}

A two-day workshop was organized to group the identified issues into cross-cutting challenges and to examine their policy implications for the EU. Apart from participants from BEPA and JRC-IPTS, there were 22 representatives from several Directorates-General of the EC, plus 19 experts from around the world who represented the six thematic areas, including foresight practitioners. All participants were requested to prepare for the workshop by familiarizing themselves with the earlier results and by developing their own proposals for cross-cutting challenges through interesting combinations of issues that were highlighted in the RPM analysis.

With the help of the RPM web-applet, the workshop participants could alter criterion weights and immediately see the impacts of these changes on the results: indeed, one reason for adopting the RPM approach was that it admits incomplete information about criterion weights and allows different interpretations of their plausibility. In addition to the numerical statistics of the assessments, participants were provided with information about the core issues and the borderline issues that had a core index value of $>50 \%$ in one or more of the three analyses. For an example, see Table 1 which shows seven issues out of 42 in the area of defence and security. A major war by 2020 , for instance, was a core issue in the rare event-oriented analysis, as it was seen as highly improbable but yet important due to its shattering consequences.

Participants then prepared proposals for cross-cutting challenges that would combine at least three different issues into a comprehensive story which would elucidate how this challenge could become reality and how the EU could respond to it through adequate policies. At least one of the three issues had to be among the top-10 core issues in one of the three different analyses, and the challenges were required to contain issues from at least two of the six areas that were analysed. In this way, the RPM analysis
Table 1. Core/borderline status of selected issues in area of defence and security

\begin{tabular}{lll}
\hline Issue & $\begin{array}{l}\text { Borderline } \\
\text { issue }>50 \%\end{array}$ & $\begin{array}{l}\text { Core issue } \\
100 \%\end{array}$ \\
\hline $\begin{array}{l}\text { A major war by } 2020 \\
\text { NATO will become more open to } \\
\text { outside partnerships }\end{array}$ & $\mathrm{R}$ \\
$\begin{array}{l}\text { Terrorists and small radicalized groups } \\
\text { will use more and more sophisticated } \\
\text { forms of attacks }\end{array}$ & $\mathrm{V}$ & $\mathrm{M}$ \\
$\begin{array}{l}\text { State's ability to guarantee security of } \\
\text { citizens will increase in Western world }\end{array}$ & $\mathrm{M}$ & \\
$\begin{array}{l}\text { Interdependency of internal and external } \\
\text { security is growing in EU }\end{array}$ & $\mathrm{R}$ \\
$\begin{array}{l}\text { Pervasive sensors for real-time surveil- } \\
\text { lance are widely diffused on a global } \\
\text { scale by 2020 }\end{array}$ & $\mathrm{M}$ & $\mathrm{M}$ \\
$\begin{array}{l}\text { Investments in defence will carry on } \\
\text { declining in world }\end{array}$ & $\mathrm{V}$ \\
\hline
\end{tabular}

$\mathrm{M}=$ mean-oriented analysis, $\mathrm{V}=$ variance-oriented analysis, $\mathrm{R}=$ rare eventoriented analysis

assisted in focusing on the most pertinent issues among which the workshop participants created novel interlinkages by formulating cross-cutting challenges and by envisioning corresponding EU policies and actions in domains such as: resource allocation; investment; regulation; policy coordination (horizontal, vertical, Open Method of Coordination); institutional changes; and the role of EU in relation to global governance. Table 2 provides an example of such a cross-cutting challenge that synthesizes issues from different thematic areas.

The participants generated collectively a set of 22 cross-cutting challenges. These were built on a number of individual cross-cutting challenges developed prior to the final workshop by both JRC-IPTS and workshop participants, such as the one presented in Table 2. These 22 cross-cutting challenges were then prioritized by discussing them in the light of three solution-oriented criteria related to their importance at the EU level. This discussion was the basis for reaching agreement on the final three overarching challenges at the end of the workshop. Specifically, these criteria were:

- Urgency: Is the challenge likely to provoke impacts that require urgent actions at EU level?

- Tractability: Can solutions to the challenge be identified and implemented? Does the EU have the institutional capacity to act on this challenge?

- Impact: Are the actions to be taken by the EU expected to have a major global positive impact?

A re-consideration of the policy agenda of BEPA, together with a collective analysis of all issues and cross-cutting challenges, made it possible to group 
Table 2. Example of a cross-cutting challenge consisting of issues from all three analyses and from different thematic areas (demography, environment, and defence and security); font styles of issue codes refer to results obtained in different RPM analyses $(<\mathrm{http}$ ://foresight.jrc.ec .europa.eu/survey issues.pdf $>$, accessed 16 September 2011)

Area No. Issue code $\quad \begin{aligned} & \text { Key words from issue description } \\ & \text { (optional) }\end{aligned}$

Save natural resources (water, food) to prevent conflicts over their scarcity and other impacts such as migration

\begin{tabular}{|c|c|c|}
\hline 1 & DI04 & Massive migration due to climate change \\
\hline 3 & ENV03 & $\begin{array}{l}\text { Global under-pricing and } \\
\text { overconsumption of water }\end{array}$ \\
\hline 3 & ENV68 & $\begin{array}{l}\text { Global decline of freshwater availability } \\
\text { leading to an increase in water } \\
\text { scarcity }\end{array}$ \\
\hline 3 & ENV70 & $\begin{array}{l}\text { Global decline in biodiversity and loss } \\
\text { of ecosystems services }\end{array}$ \\
\hline 6 & DS13 & Attacks on infrastructure facilities \\
\hline 6 & DS15 & A major war by 2020 \\
\hline 6 & DS81 & $\begin{array}{l}\text { Pervasive sensors for real-time surveil- } \\
\text { lance widely diffused }\end{array}$ \\
\hline
\end{tabular}

Global decline in the quantity and quality of available fresh water seems to lead to a dramatic increase in water scarcity in many parts of the world, and its impacts will be felt more intensely in the period 2025-50. According to the OECD (2008), 2.8 billion, or $44 \%$, of the world's population lives in areas of high water stress. There is a risk of global water bankruptcy due to humanity's consistent under-pricing of water and its consequent waste and overuse. Measures to save natural resources (mainly water and food) have to be applied worldwide. In addition, technologies have to be developed and/or applied to provide sufficient water and food in many parts of the world

the individual cross-cutting challenges proposed by workshop participants into five categories and then, on the second day of the workshop, into 22 collectively developed cross-cutting challenges divided in four clusters:

- global governance

- natural capital

- society

- economy.

By the end of the workshop, a workable agreement had been reached on the definition of the following three overarching challenges:

- The need to change current ways in which essential natural resources are used.

- The need to anticipate and adapt to societal changes.

- The need for more effective and transparent governance for the EU and the world.

All these challenges exhibit a global scope and require action at EU level through appropriately aligned crosscutting policies that implement effective joint responses. These challenges also served as a basis for the following three broad recommendations which, according to the workshop participants, had not yet received sufficient attention in the policy and decision processes (Boden et al. 2010):

- The need to change the uses of essential natural resources by aligning all policy realms towards sustainability, extending from policy design through implementation to evaluation.

- The need to anticipate and adapt to societal challenges by building on social diversity and information and communications technologies to enable citizens' empowerment.

- The need for more effective and transparent governance that allows institutions to anticipate future challenges and to turn these into opportunities by embedding FTA in their decision-making processes.

\subsection{Reflections on the exercise}

Overall, the exercise can be viewed as a collective sense-making process where emerging issues were first identified and then synthesized into challenges at the EU level. The vocal satisfaction expressed by the workshop participants suggests that there is considerable potential in carrying out similar or analogous exercises based on the same methodological approach. Participants, especially policy-makers, found that they could express and explore their ideas freely and interactively. They also said that they received useful feedback from participants representing different policy areas, because this helped them to see challenges from alternative viewpoints and explore solutions that would constitute systemic responses. In its approach, the workshop evolved from a loosely structured discussion of issues resulting from the scanning of reports to a collective sense-making process that focused on how such issues could be brought together into cross-cutting challenges and how such challenges could be explored in view of EU-level policy implications.

The traceability of cross-cutting challenges and recommendations was supported by the appropriate coding of issues and challenges that were generated during the exercise. This has been helpful when communicating the results to outside parties, because it has increased the transparency and legitimacy of the results. To cite an example, the recommendations have been useful in discussions within the EC, for instance on the sustainable use of natural resources which may become a source of conflicts in the future. The final report (Boden et al. 2010) has been referenced in the Communication on the Innovation Union (SEC 2010), particularly when describing grand challenges that have to be addressed through European policy-making.

\section{Implications for horizon scanning}

The recent proliferation of horizon-scanning activities is partly linked to the popularity of the "wisdom of the 
crowds' (Duboff 2007) which suggests that the engagement of a large number of scanners helps draw attention to phenomena that qualify as indicators of emerging policy issues. Indeed, in comparison with more structured approaches - such as Delphi studies - a distinctive and defining feature of horizon scanning is that there are no strong a priori constraints on which signals could count as relevant. Also, because judgements on relevance are taken later, horizon scanning is inherently a bottom-up process where results from individual sense-making activities are followed by collective processes where the scanners take stock of and learn from each others' signals.

From the viewpoint of policy-making, however, this type of 'bottom-up' process implies that the list of prioritized issues may not be very coherent (Bunn and Salo 1993). Indeed, the resulting list may appear fragmented and lead to the development of piecemeal and possibly even conflicting action plans. It may therefore be beneficial to synthesize issues into a smaller number of internally consistent theme clusters which reflect the full scope of the issues and which highlight interconnections that might otherwise escape attention. Yet, an inherent difficulty in this type of clustering-which requires and fosters collective sense-making - is that the number of possible combinations can be enormous. For example, if there are 40 issues from which clusters of containing three issues are to be built, there would be nearly ten thousand possible combinations $(40 ! / 3 ! 37 !=9880)$. Due to this mathematical reality, it is practically impossible to evaluate all combinations systematically.

In this setting, it can be beneficial to proceed iteratively, possibly by following 'rules of thumb', for instance by:

- Building an initial set from one or few issues that appear to be particularly significant.

- Expanding such sets with additional issues that are consistent with the ones that have been already selected.

- Continuing until the resulting set has reasonably many issues and sufficiently broad coverage.

Because these steps rely on subjective judgements that call for creative sense-making, they may be best enacted in workshops that offer opportunities for intensive interaction and shared knowledge creation. Furthermore, the clusters (akin to the 'cross-cutting challenges' which combined issues from at least two areas in the case study) may have to be described at a more abstract and general level than the issues from which they were built. In consequence, the clusters may not be all that easy to interpret, especially if there are no pointers to underlying evidence about the issues or the insights that may have guided their aggregation. One may therefore wish to strive for a traceability that allows users to explore which issues a given cluster was built from and which reasons guided its formation.
A third concern is that if the resulting clusters are truly comprehensive, they may have policy implications in several areas of administrative responsibility. But if the policy-makers in these areas are autonomous, or represent different 'administrative silos', it may be difficult to shape broad policies that they would be fully committed to, because such commitments could be seen as a threat to their autonomy. This notwithstanding, collective sense-making activities spurred by cluster formation can still be fruitful, because they highlight the interconnectedness of policy actions and, by doing so, provide pointers to actions that may be best executed in a loosely coordinated fashion. In this way, horizon scanning activities can, at best, contribute to the design of systemic policies which - far from being monolithic and inflexible - contribute to the attainment of systemic policy objectives by supporting the timely recognition of the interconnectedness of actions.

Based on their experiences from the exercise on 'Scanning for emerging science and technology issues', Amanatidou et al. (2012) concluded that the analysis of signals and emerging issues as well as ensuing workshops need to be structured around specific policy challenges and aligned with the agendas of policy-makers. In particular, linkages to prevalent issues that were already on the radar of policy-makers were seen to contribute to the usefulness of the exercise. Seen from this perspective, the BEPA exercise suggests that although the issues as such may be known, they merit renewed attention if their broader significance for society and policy-making has not yet been sufficiently addressed.

The engagement of stakeholders into collective sensemaking in horizon scanning may follow different organizational models. Specifically, Weber et al. (2012) consider three ideal-type models for FTA, namely:

- individual projects or programmes of limited duration and with targeted objectives

- dedicated units providing continuous input to their embedding or mother organizations

- networks as informal yet stable settings that allow for the bundling or coordination of resources and competencies

Following this classification, we believe that the integration of these different ideal-types can be useful in establishing anticipatory systems. For example, while the institutionalization of scanning activities serves to establish close links with decision-makers and makes it possible to build up capabilities on continuous basis, the contracted external services and organized international networks can still allow for a more rapid and flexible mode of carrying out extensive scanning activities. All in all, the systematic engagement of diverse stakeholders calls may call for an equally diverse range of organizational approaches that establish appropriate incentives for effective stakeholder participation. Seen from this perspective, the BEPA 
exercise can also be seen as an example of building an international anticipatory system, which increases its relevance for initiatives such as the European Forum on Forward Looking Activities and the Joint Programming in Research (Könnölä et al. 2012).

To sum up, we have illustrated that horizon-scanning activities need not be limited to the collection of future-oriented observations. Rather, the scope of these activities can be extended to include creative and collective sense-making processes for synthesizing observations into cross-cutting challenges and also for exploring the policy implications of these challenges in collaborative workshops. From this perspective, we have presented the foresight exercise 'Facing the future: Time for the EU to meet global challenges' which has informed the strategy processes of BEPA and JRC, has also influenced other stakeholders, and has served as an input to the recent EC Communication on the Innovation Union. Overall, it appears the methodological approach in this exercisewhich had well-defined phases for the systematic 'bottom-up' scanning of issues and for the prioritization and clustering thereof - is viable even in other contexts where there is a need to build shared understandings about the prospects of cross-cutting coordination in support of systemic policy objectives.

\section{Acknowledgements}

The views expressed are purely those of the author and may not in any circumstances be regarded as stating an official position of the European Commission.

\section{Notes}

1. See <http://horizonscanning.defra.gov.uk> accessed 26 September 2011. See also Schultz (2006).

2. Effie Amanatidou, Anette Braun, Ville Brummer and Mika Mannermaa supported JRC-IPTS in reviewing four out of the six areas.

3. During the International Seville Conference 2008 on Future-oriented Technology Analysis a 'big picture' survey was conducted on trends, drivers, wild cards, discontinuities and weak signals likely to share the future (Saritas and Smith 2011). The particularly novel issues from this survey were added to the issues collected from the literature review.

4. These issues plus the 73 additional issues identified by the survey participants can be found at <http:// foresight.jrc.ec.europa.eu/bepa.html $>$ accessed 18 September 2011.

\section{References}

Amanatidou, E., Butter, M., Carabias, V., Könnölä, T. et al. (2012) 'On concepts and methods in horizon scanning:
Lessons from initiating policy dialogues on emerging issues', Science and Public Policy, 39: 208-22.

Anderson, W. (2005) 'Wiring up Whitehall: Ensuring effective cross departmental activity', Journal of Security Sector Management, 3: 1-20.

Ansoff, H. I. (1975) 'Managing strategic surprise by response to weak signals', Califonia Management Review, XVIII: 21-33.

Blackburn, S., Cudd, P. and Hawley, M. (2010) 'A horizon scanning system for identifying new telehealth innovations', Global Telemedicine and eHealth Updates: Knowledge Resources, 3, pp. 326-30. <http://www.medetel.eu/index .php?rub $=$ proceedings\&page $=$ info $>$ accessed 14 September 2011.

Boden, M., Cagnin, C., Carabias, V., Haegeman, K. and Könnölä, T. (2010) 'Facing the future: Time for the EU to meet global challenges', 24364 EN, 6/2010. Luxembourg: Office for Official Publications of the European Commission.

Botterhuis, L., van der Duin, P., de Ruijter, P. and van Wijck, P. (2010) 'Monitoring the future. Building an early warning system for the Dutch Ministry of Justice', Futures, 42: 454-465.

Brummer, V., Könnölä, T. and Salo, A. (2008) 'Foresight within Era-Nets: Experiences from the preparation of an international research programme', Technological Forecasting and Social Change, 75: 483-95.

Brummer, V., Salo, A., Nissinen, J. and Liesiö, J. (2011) 'A methodology for the identification of prospective collaboration networks in international R\&D programs', International Journal of Technology Management, 54: 369-89.

Bunn, D. W. and Salo, A. (1993) 'Forecasting with scenarios', European Journal of Operational Research, 68: 291-303.

Dervin, B. (1998) 'Sense-making theory and practice: An overview of user interests in knowledge seeking and use', Journal of Knowledge Management, 2: 36-46.

Duboff, R. S. (2007) 'The wisdom of (expert) crowds', Harvard Business Review, 85: 28.

European Communities (2009) 'The world in 2025. Rising Asia and socio-ecological transition', EUR 23921 EN. Luxembourg: Office for Official Publications of the European Commission.

Fuerth, L. S. (2009) 'Foresight and anticipatory governance', Foresight, 11: 14-32.

Georghiou, L. and Cassingena Harper, J. (2011) 'From priority-setting to articulation of demand: Foresight for research and innovation policy and strategy', Futures, 43: 243-51.

Glenn, J. C., Gordon, T. J. and Florescu, E. (2010) State of the Future, The Millenium Project. Washington DC: The Millennium Project.

Graefe, A., Luckner, S. and Weinhardt, C. (2010) 'Prediction markets for foresight', Futures, 42: 394-404.

Haegeman, K., Cagnin, C., Könnölä, T., Dimitrov, G. and Collins, D. (2011) 'Web 2.0 for foresight: Experiences on an innovation platform in European agenda setting' in Proceedings of the FTA 2011 Conference, Seville, <http:// foresight.jrc.ec.europa.eu/fta_2011/> accessed 26 September 2011.

Hiltunen, E. (2008) 'The future sign and its three dimensions', Futures, 40: 247-60.

Könnölä, T. and Unruh, G. C. (2007) 'Really changing the course: The limitations of environmental management systems for innovation', Journal of Business Strategy and the Environment, 16: 525-37.

Könnölä, T., Brummer, V. and Salo, A. (2007) 'Diversity in foresight: Insights from the fostering of innovation ideas', Technological Forecasting and Social Change, 74: 608-26. 
Könnölä, T., Haegeman, K. and Guy, K. (2012) 'Embedding foresight in transnational research programming', Science and Public Policy, 39: 191-207.

Könnölä, T., Scapolo, F., Desruelle, P. and Mu, R. (2011) 'Foresight tackling societal challenges: Impacts and implications on policy-making', Futures, 43: 252-64.

Kuosa, T. (2010) 'Futures signals sense-making framework (FSSF): A start-up tool to analyse and categorise weak signals, wild cards, drivers, trends and other types of information', Futures, 42: 42-8.

Liesiö, J., Mild, P. and Salo, A. (2007) 'Preference pogramming for robust portfolio modeling and project selection', European Journal of Operational Research, 181: 1488-505.

Linstone, H. (1999) 'Complexity science: Implications for forecasting', Technological Forecasting and Social Change, 62: 79-90.

Martin, B. and Johnston, R. (1999) 'Technology foresight for wiring up the national innovation system: Experiences in Britain, Australia and New Zealand', Technological Forecasting and Social Change, 60: 37-54.

McKinsey \& Company (2009) 'How companies are benefiting from Web 2.0: McKinsey global survey results', $<$ http://www .mckinseyquarterly.com/ $>$ accessed 14 September 2011.

Mendonça, S., Pina e Cunha, M., Kaivo-oja, J. and Ruff, F. (2004) 'Wild cards, weak signals and organisational improvisation', Futures, 36: 201-18.

Möller, K. (2010) 'Sense-making and agenda construction in emerging business networks - How to direct radical innovation', Industrial Marketing Management, 39: 361-71.

Nelson, R. (2010) 'Extending foresight: The case for and nature of foresight 2.0', Futures, 42: 282-94.

Nonaka, I. (1994) 'A dynamic theory of organizational knowledge creation', Organization Science, 5: 14-37.

OECD. (2008) OECD Environmental Outlook to 2030. Paris: OECD.

Rossel, P. (2011) 'Beyond the obvious: Examining ways of consolidating early detection schemes', Technological Forecasting and Social Change, 78: 375-85.
Salo, A., Brummer, V. and Könnölä, T. (2009) 'Axes of balance in foresight: Reflections from FinnSight 2015', Technology Analysis and Strategic Management, 21: 987-1001.

Saritas, O. and Smith, J. E. (2011) 'The big picture - trends, drivers, wild cards, discontinuities and weak signals', Futures, 43: $292-312$.

Scharmer, K. O. (2000) 'Organizing around not-yet-embodied knowledge'. In: Von Krogh, G., Nonaka, I. and Nishiguchi, T. (eds) Knowledge Creation: A Source of Value, pp. 36-60. London: MacMillan.

Schoen, A., Könnölä, T., Warnke, P., Barré, R. and Kuhlmann, S. (2011) 'Tailoring foresight to field specificities', Futures, 43: 232-42.

Schultz, W. L. (2006) 'The cultural contradictions of managing change: Using horizon scanning in an evidence-based policy context', Foresight, 8: 3-12.

SEC (2010) 1161 Final. Commission Staff Working Document A Rationale for Action, Accompanying the Europe 2020 Flagship Initiative Innovation Union $\operatorname{COM}(2010)$ pages 9 and 89, <http://ec.europa.eu/research/innovation-union/pdf/ rationale_en.pdf $\#$ view $=$ fit\&pagemode $=$ none $>$, accessed 16 September 2011.

Sutherland, W. J., Bardsley, S., Bennun, L., Clout, M. et al. (2011) 'Horizon scan of global conservation issues for 2011', Trends in Ecology and Evolution, 26: 10-6.

Taleb, N. N. (2007) The Black Swan: The Impact of Highly Improbable. New York: Random House.

du Toit, A. (2003) 'Knowledge: A sense making process shared through narrative', Journal of Knowledge Management, 7: 27-37.

Weber, M., Cassingena Harper, J., Könnölä, T. and Carabias, V. (2012) 'Coping with a fast-changing world: Towards new systems of future-oriented technology analysis', Science and Public Policy, 39: 153-66.

Weick, K. (1995) Sensemaking in Organizations. Thousand Oaks, CA: Sage. 